\title{
SINE WAVE FILTERS DESIGN FOR AC MOTOR DRIVES WITH GENETIC ALGORITHMS
}

This paper proposes a suitable design methodology of the filter used at the output of inverters for AC motor drives. While it allows to achieve the best tradeoff among different design constraints that are difficult to include in standard design methods, such an approach is able to simultaneously consider several technical issues such as losses and voltage drops of the filter, total harmonic distortion of currents and voltages as well as economic aspects. Accordingly, the proposed procedure determines the optimal values of the filter parameters by exploiting simulations of accurate model of the electrical drive and genetic algorithms. Hence, no rough approximations or complex analytical calculations are performed to suitably design the inverter output filter. The method was validated by means of various tests performed on two different induction motor drives, considering some significant design constraint scenarios.

Keywords: Power filters, variable speed drives, genetic algorithms, design optimization.

\section{Introduction}

Nowadays, the use of electrical drives is becoming more and more pervasive because of considerable price fall while their technical performance has largely increased [1]. On the other hand, if the electrical machines are fed by power converters because of their high switching frequency, additional stresses and drawbacks are experienced in comparison with line frequency powered motors [2 and 3], such as:

- Overvoltage to stator motor windings;

- Bearing currents;

- Acoustic noise;

- Electromagnetic emissions;

- Additional Losses.

The above mentioned effects are strictly related to very fast commutation of inverter power devices which, in some applications, can lead to unacceptable consequences as they cause premature failure of the motor, especially when a long cable is used to connect the inverter and the motor. In those cases, additional filters connected between the inverter and electrical machine could be required [ 4 and 5].

Various filter typologies have been suggested, depending on desired system performance and cost constraints. The cheapest solution able to reduce the $\mathrm{dV} / \mathrm{dt}$ applied to motor windings is given by the use of simple output chokes or $\mathrm{dV} / \mathrm{dt}$ filters; both of them are able to reduce the stress on motor winding insulation but only when a short cable length is used to connect the inverter to the motor. In fact, due to reflection phenomena of the voltage and current waves along the cable, also related with high $\mathrm{dV} / \mathrm{dt}$ values of inverter power devices, an overvoltage up to twice the DC bus value could be applied to motor terminals if a critical cable length is overtaken. Moreover, as the waves reflection phenomena along the cable occurs at its own frequency, they can interact with PWM pulses of similar period causing the increase of voltage stress, theoretically, up to four times the DC bus voltage value. Furthermore, such kinds of filters are not effective in terms of reduction of bearing currents, acoustic noise, and do not change the drive EMI emission.

Unlike the above solutions, more sophisticated but expensive products are used to provide a nearly sinusoidal phase to phase voltage to motor terminals, thus the negative effects related to the square-wave voltage impulses are significantly reduced. They are normally known on the market as sine wave filters (SWF) [6 and 7].

Other technical solutions have been proposed to further reduce the effects of the high frequency common mode currents. The most popular ones act by modifying the PWM switching pattern while others use three phase coupled magnetic circuits and/or additional power electronic devices to create a preferential common mode current path to the DC bus [8, 9 and 10]. The effectiveness of each solution was qualitatively summarized as reported in Table 1.

As regards the standard analytical filter design methods, most of them exploit the filter transfer function and a simplified model of the electrical motor to compute the system frequency response [11, 12 and 13]. Basically, these procedures establish the filter technical constraints as the rising time, settling time, overshoot

\footnotetext{
* ${ }^{1}$ Mario Cacciato, ${ }^{1}$ Giuseppe Scarcella, ${ }^{1}$ Giacomo Scelba, ${ }^{2}$ Pavol Spanik

${ }^{1}$ Department of Electrical, Electronics and Computer Science, University of Catania, Italy

${ }^{2}$ Department of Mechatronics and Electronics, Faculty of Electrical Engineering, University of Zilina, Slovakia

E-mail: giacomo.scelba@dieei.unict.it
} 
and other properties; then, the filter parameters are calculated by solving a mathematical system of equations obtained using the filter transfer function. As a consequence, the design issues that are not directly related to the filter transfer function, such as losses, harmonic distortion of the currents $\left(\mathrm{THD}_{\mathrm{I}}\right)$ and voltages $\left(\mathrm{THD}_{\mathrm{v}}\right)$, voltage drop, costs, EMI and acoustic noise, cannot be taken into account.

In order to consider at the same time all the previously mentioned issues, a design procedure is proposed in this paper, able to determine the optimal value of the SWF components, by combining the attitude of Genetic Algorithms (GA) to simultaneously evaluate a population of many sets of filter components solutions, with the capability to verify the fulfillment of the design constraints using a Graphical Simulation Tool (GST) to model and simulate the electrical drive [14 and 15]. This procedure is able to reach the optimal filter design with a reasonably low computation effort while including system nonlinearities of the drive model. Moreover, this methodology can be easily extended to different filters and drive configurations in many operating conditions, only by modifying the electrical circuit, loads and speeds used in the GST [16]. The effectiveness of the algorithm was verified by considering two different AC drive systems, as it is reported in the following sections.

Behavior of filter topologies

Table 1

\begin{tabular}{|l|c|c|c|}
\cline { 2 - 4 } \multicolumn{1}{c|}{} & \multicolumn{3}{c|}{ Filter type } \\
\hline Filter effect & Output chokes & $d v / d t$ & Sine wave \\
\hline Motor insulation & - & + & ++ \\
\hline Bearing stress & - & $-t^{+}$ & + \\
\hline EMI & - & - & - \\
\hline Leakage current & - & - & - \\
\hline Acoustic noise & - & - & ++ \\
\hline
\end{tabular}

\section{Design technique of SWFS based on GA}

The design procedure is described in the following subsections and it can be applied to all filter topologies in principle. In order to consider a useful real case, the most common filter topology used in industrial applications was studied; its scheme is shown in Fig. 1 and its transfer function is given by:

$H(s)=\frac{1+s R C}{s^{2} L C+s\left(R+R_{L}\right) C+1}$

This filter is connected between the terminals of the three phase inverter and the electrical machine; a three phase induction machine is considered in this analysis. The filter inputs $\left(A_{l}, B_{l}\right.$, $C_{l}$ ) are electrically connected to the inverter output terminals while the filter outputs $\left(A_{2}, B_{2}, C_{2}\right)$ are coupled to motor terminals. The block diagram of the analyzed AC drive is shown in Fig. 2; it is worth noting that a standard industrial electrical drive is considered, consisting of a diode rectifier, a DC bus capacitive filter, a three phase voltage-source inverter, a RLC filter and an induction motor. The GST used in this study is the SymPowerSystem library of the graphical programming language Simulink, but other GST could be also used to implement the proposed filter design method [17].

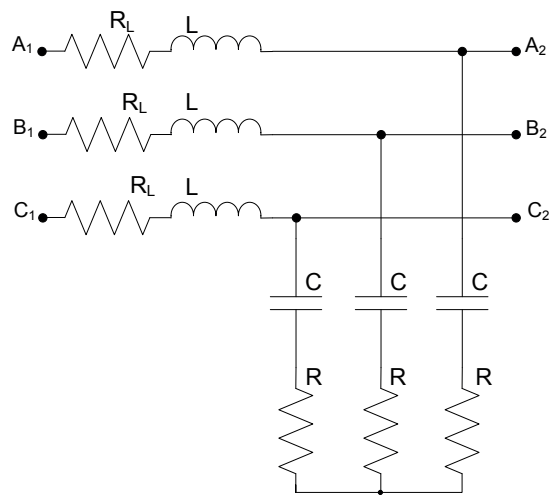

Fig. 1 Scheme of considered filter topology

\section{(a) Design Constraints}

In order to optimize the filter size, some additional blocks shown in Fig. 2 are specifically used to compute additional parameters necessary to the GA and used to verify the design specifications. In particular, according to the filter constraints, the values of the resistance $R$, capacity $C$ and inductance $L$ are set by monitoring the following variables:

The total harmonic distortion of the phase current and line to line voltage labeled $T H D_{I}$ and $T H D_{r}$, respectively. High THD values would end up with the increase of iron and copper losses as well as torque and speed ripples of the electrical motor. These quantities are calculated in simulation, by means of eqn. 2, where $S_{h}$ and $S_{l}$ are the rms amplitude values of the $t h$ and first harmonics, respectively.

$T H D \%=\frac{\sqrt{\sum_{h=2}^{\infty} S_{h}^{2}}}{S_{1}} \cdot 100$

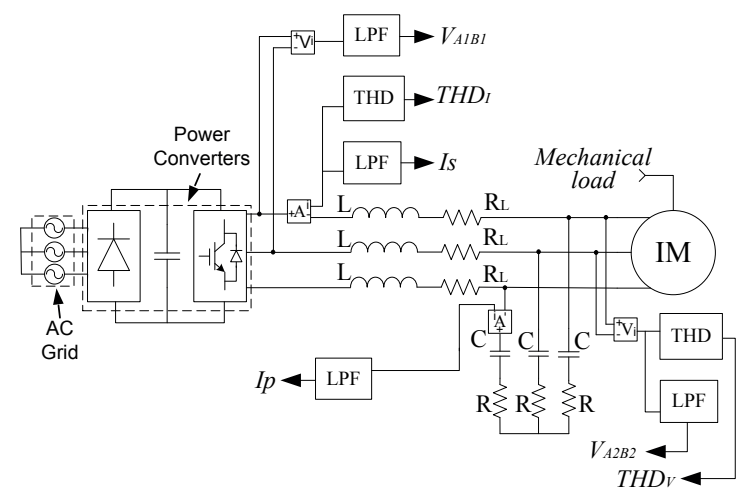

Fig. 2 Block diagram of the electrical ac drive implemented in the GST 
The voltage drop $D V$ on longitudinal elements of the filter is another key issue that must be minimized by design to avoid a significant reduction of maximum voltage capability of the drive.

In percentage, such a quantity is given by:

$\Delta V \%=\frac{V_{A_{1} B_{1}}-V_{A_{2} B_{2}}}{V_{A_{1} B_{1}}} \cdot 100$

where $V_{A I B I}$ is the amplitude value of the line to line voltage measured at the filter input terminals, while $V_{A 2 B 2}$ is the equivalent voltage value measured at the filter output.

Filter efficiency plays a very important role as it affects the performance of the whole drive. The filter losses $P_{\text {loss }}$, of elements $R_{L}$ and $R$, can be calculated as:

$P_{\text {loss }} \%=\frac{3 \cdot\left(R_{L} \cdot I_{s}^{2}+R \cdot I_{p}^{2}\right)}{P_{n}}$

where $R_{L}$ is the parasitic resistance of the inductance $\mathrm{L}$ and $R$ is the damping resistor added for control reasons, while $P_{n}$ is the drive rated power.

Another important design issue considered in the following analysis is the investment cost $I C$, evaluated by considering the linear relationship (5), as a function of the capacity $C$ and inductance $L$ values. The values of $C_{L}, c_{L}, C_{C O}, C_{C}$ are related to components technologies and technical specifications required to $L$ and $C$ [18]. Mainly depending on the voltage class of the drive considered in this study, the following coefficient values were settled on the basis of commercial data $C_{L 0}=33.3 €, c_{L}=1.47 € / \mathrm{mH}$, $C_{C 0}=6.3 €, C_{C}=0.48 € / \mu F$.

The parameter $R$ is purposely not included in eqn. 5 because low power resistors are normally used and their cost is negligible compared to other passives. Finally, IC term provides the cost per phase of the filter, thus the total cost is given by $3 \cdot I C$.

\section{(b) Genetic Algorithm}

Generally speaking, GAs are widely used to solve many optimization and synthesis problems, and work evaluating the previously defined target function that must be optimized, starting from some randomly selected points of the definition domain. They are used recursively to generate a new set of points. Gradually, the points in the generated population will approach local maxima and minima of the target function. Since information from many different regions is used, a GA can move away from a local maximum or minimum if the population finds better function values in other areas of the definition domain, avoiding to remain trapped in a local maximum or minimum of the target function.

In order to identify the best filter configuration, a suitable GA of characteristics listed in Table 2 is exploited to minimize the target function $f_{o b}$ including a linear combination of the aforementioned technical constraints. It can be noted that the domain of $f_{o b}$ is defined by the adopted minimum and maximum values of filter parameters. These limits depend on the rated voltage and current of the drive while the weights associated to each design constraint are strictly related to the importance given to such constraints by the designer. In this paper, three different target functions were taken into consideration as reported in Table 3. Considering the target functions expressions, the constant $k$ was chosen on the basis of the experience. In particular, $k$ was fixed in the range $3 \div 7$ to achieve the most suitable filter configurations for $\mathrm{AC}$ drives with a rated power lower than $20 \mathrm{~kW}$.

Technical specification of the GA adopted in the filter design procedure.

Table 2

\begin{tabular}{|l|c|}
\hline Population Size & 100 individuals \\
\hline Max number of generations & 15 \\
\hline Selection function & Stochastic Universal Sampling \\
\hline Crossover function & Single Point \\
\hline Mutation function & Uniform \\
\hline Resolution & 11 bit \\
\hline Elitism & $10 \%$ \\
\hline Number of parameters & 3 \\
\hline Resistance Variation & $0.1 \Omega<R 100 \Omega$ \\
\hline Inductance Variation & $0.1 \mathrm{mH}<L<100 \mathrm{mH}$ \\
\hline Capacity Variation & $0.1 \mu F<C<100 \mu F$ \\
\hline Stop Criteria & $\mathrm{max}$ generation \\
\hline
\end{tabular}

Target functions Table 3

\begin{tabular}{|l|l|}
\hline$f_{o b}{ }^{A}$ & $T H D_{1} \%+T H D_{V} \%+\Delta V \%+k P_{\text {loss }} \%$ \\
\hline$f_{o b}{ }^{B}$ & $T H D_{1} \%+T H D_{V} \%+\Delta V \%+k P_{\text {loss }} \%+I C / 10$ \\
\hline$f_{o b}{ }^{C}$ & $T H D_{1} \%+T H D_{V} \%+\Delta V \%+k P_{\text {loss }} \%+I C$ \\
\hline
\end{tabular}

As it is shown in Table 3, the first target function $f_{o a}^{A}$ does not include the filter costs while the other two functions $f_{o b}{ }^{B}$ and $f_{o b}{ }^{C}$ combine this economic constraint with different weights.

\section{(c) Design Procedure}

The design procedure suitably exploits the two tools GST and GA in order to minimize $f_{o b}$. A schematic representation of the method is depicted in the flow chart of Fig. 3 and can be explained as follows. Initially, a first random generation of $(R, L$, $C$ ) candidates is provided; then, the GST is exploited to simulate the motor drive adopting the above filter parameter sets. The simulation provides the corresponding value of filter performance that is used to evaluate the objective function $f_{o b}$. Soon after, the Stop Criteria is evaluated and if it is not satisfied, a next generation of $R, L, C$ values is provided to the GST, repeating the simulation with new set of components. 
In order to have a fixed execution time of the algorithm, in the proposed method the Stop Criteria was fixed equal to the max number of generations.

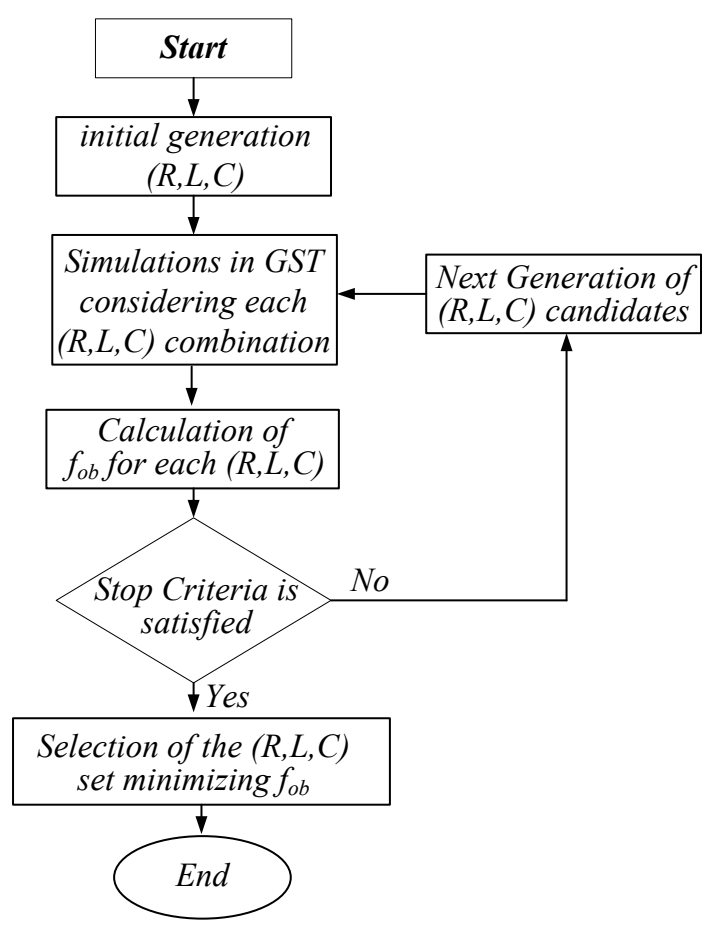

Fig. 3 Flow chart of optimal filter sizing procedure

\section{Case study}

The design method was validated by considering two induction motor drives whose motor specifications are listed in Table 4 . In order to simplify the calculation, power device losses and magnetic saturation of the induction machine were neglected [19, 20 and 21].

The reliability of the design method was verified by running it numerous times considering the same $\mathrm{AC}$ drive configuration, but modifying the initial population of $(R, L, C)$ candidates. In spite of the initial set of R, L, C, its final values calculated at the end of the procedure are very close. As a matter of fact, considering three different initial values of filter parameters with Motor I and using the objective function $f_{o b}^{A}$, the trajectories followed and final values achieved of set $(\mathrm{R}, \mathrm{L}, \mathrm{C})$ are shown in Fig. 4. The drive operating conditions are: rated frequency, amplitude modulation index $m_{a}=0.5$, load torque $20 \mathrm{Nm}$ and inverter switching frequency equal to $5 \mathrm{kHz}$. As it is shown in Fig. 4, depending on the initial values the procedure follows different trajectories and converges to very close values of the filter parameters, confirming the consistency of the method. In this case, considering the approximation due to the commercial components, the values are
$\mathrm{R}=1.0 \Omega, \mathrm{C}=3.5 \mu \mathrm{F}$ and $\mathrm{L}=6.0 \mathrm{mH}$. The performances of the $\mathrm{SWF}$ are reported in Table 5 .

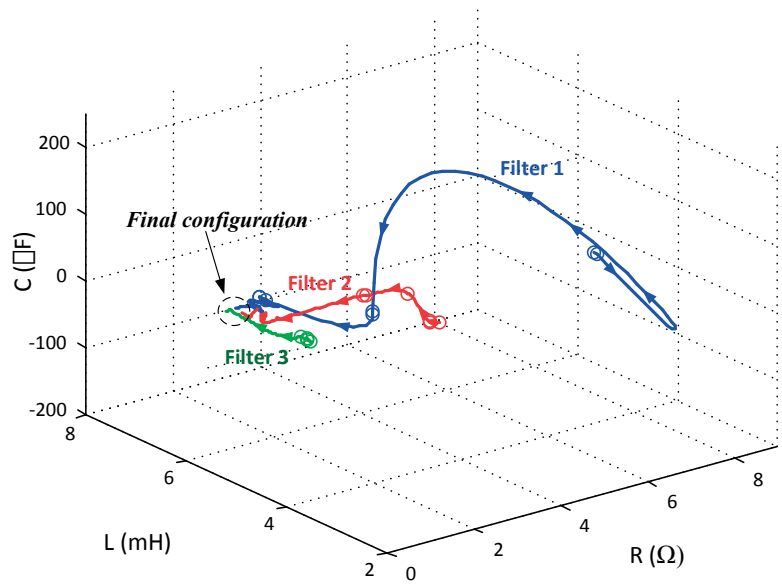

Fig. 4 Trajectories of elaborated sets of $R, L, C$ values

Technical specifications of Motors I and II

Table 4

\begin{tabular}{|l|c|c|}
\hline Rated Power & $4000 \mathrm{~W}$ & $15000 \mathrm{~W}$ \\
\hline Rated Voltage & $400 \mathrm{~V}$ & $400 \mathrm{~V}$ \\
\hline Stator Resistance & $1.405 \Omega$ & $0.2147 \Omega$ \\
\hline Stator Leakage Inductance & $5.839 \mathrm{mH}$ & $0.991 \mathrm{mH}$ \\
\hline Rotor Resistance & $1.395 \Omega$ & $0.2205 \Omega$ \\
\hline Rotor Leakage Inductance & $5.839 \mathrm{mH}$ & $0.991 \mathrm{mH}$ \\
\hline Magnetizing Inductance & $0.1722 \mathrm{H}$ & 0.06419 \\
\hline Mechanical Inertia & $0.0131 \mathrm{~kg} \cdot \mathrm{m}^{2}$ & $0.102 \mathrm{~kg} \cdot \mathrm{m}^{2}$ \\
\hline Pole Pairs & 2 & 2 \\
\hline
\end{tabular}

The proposed method can be also used to analyze the impact of the drive operating conditions on the filter performance. Hereafter, the influences of switching frequency, partial load, power rating and investment cost on the determination of the optimal filter design were studied.

Technical performances of the filter with commercial components

Table 5

\begin{tabular}{|l|c|c|c|c|c|}
\hline & $\mathrm{THD}_{\mathrm{V}} \%$ & $\mathrm{THD}_{1} \%$ & $\Delta \mathrm{V}^{\mathrm{\%}}$ & $\mathrm{P}_{\text {loss }}{ } \%$ & $\mathrm{f}_{\mathrm{ob}}{ }^{\mathrm{A}}$ \\
\hline Filter & 2.943 & 6.889 & 3.527 & 1.270 & 17.060 \\
\hline
\end{tabular}

\section{(a) Switching frequency}

Generally speaking, performance, cost and size of sine wave filter are strongly related to the switching frequency $f_{s w}$ of the inverter power devices. In fact, addressing the same filter performance, at higher inverter switching frequencies, the cutoff frequency of the filter can be broadened thus smaller filter elements are required with some positive consequences, mainly in terms of size and cost. 
The second test was carried out considering a $4 \mathrm{~kW}$ drive operating at the same conditions of the previous tests but with different $m_{a}=0.9$ and switching frequency. In this case, by applying the proposed method, different values of the filter parameters are calculated as reported in Table 6 . It is worth noting that modifying the amplitude of the fundamental phase voltage $\left(m_{a}=0.9\right), R$ value needs to be increased to maintain limited filter losses. Moreover, as the switching frequency increases, the capacitor value $C$ is considerably reduced while the inductance value $L$ is not subjected to significant variations leading to a considerable reduction of the $T H D_{I}$

After determination of the best filter parameters set for a specific switching frequency, the filter performance of such filters related with possible variations of the switching frequency were evaluated. The results of this study are summarized in Tables 7 - 9 addressing that no significant differences are detected among the three filter arrangements operating at different $f_{s w}$ except for the cutoff frequency $F_{c}$ which is higher for the filter designed for the highest $f_{s w}$.

\section{(b) Load torque}

The drive always operates at partial loads or at overload conditions. The maximum load torque considered during the filter design procedure influences the final $(R, L, C)$ set because it is strictly related with the phase current amplitude. In fact, the voltage drops on the inductive reactance and $R_{L}$ increases with the amplitude of the phase current, hence, it is necessary to reduce the $L$ value when the maximum allowed load is increased.

Moreover, as it is obvious, it is convenient to increase the section of the wires used to form the inductance to drop the stray parameter $R_{L}$, thus reducing the conduction losses. In order to evaluate how the optimal configuration of the SWF is affected by the load conditions, the proposed design procedure was applied to the same operating conditions of previous tests, with $m_{a}=0.9$, $f_{\text {sw }}=5 \mathrm{kHz}$ in correspondence with three different load conditions. The results are listed in Table 10. From the calculations, the resulting performances are similar for the three cases and they are matching good technical specifications.

The three $(R, L, C)$ component sets listed in Table 10 were considered to compute the filter performance with the drive operating in different load conditions; the results are reported in Tables $11-13$. It is worth noting that the filter design procedure confirms the aforementioned assumptions, i.e., filters designed for lower phase current amplitudes present higher losses and voltage drops when they operate at high current amplitudes, considerably affecting the performance of the drive. Fig. 5 shows a drive

Optimal filter configurations achieved considering different switching frequencies

Table 6

\begin{tabular}{|c|c|c|c|c|c|c|c|c|}
\hline $\mathrm{f}_{\mathrm{sw}}[\mathrm{kHz}]$ & $\mathrm{R}[\Omega]$ & $\mathrm{L}[\mathrm{mH}]$ & $\mathrm{C}[\mu \mathrm{F}]$ & $\mathrm{THD}_{\mathrm{V}} \%$ & $\mathrm{THD}_{1} \%$ & $\Delta \mathrm{V} \%$ & $\mathrm{P}_{\text {loss }} \%$ & $\mathrm{f}_{\mathrm{ob}}{ }^{\mathrm{A}}$ \\
\hline 5 & 7.8 & 4.3 & 7.5 & 3.3 & 9.0 & 3.8 & 1.30 & 22.7 \\
\hline 10 & 15.4 & 5.1 & 4.3 & 3.9 & 5.0 & 3.7 & 1.17 & 18.5 \\
\hline 15 & 13.9 & 4.3 & 1.8 & 5.3 & 4.3 & 4.0 & 1.19 & 14.0 \\
\hline
\end{tabular}

Technical specifications of the filter $\mathrm{R}=7.76 \Omega, \quad \mathrm{L}=4.33 \mathrm{mH}, \mathrm{C}=7.52 \mu \mathrm{F}$ designed for $f_{s w}=5 \mathrm{kHz}$

Table 7

\begin{tabular}{|c|c|c|c|c|c|c|c|}
\hline $\mathrm{f}_{\mathrm{sw}}[\mathrm{kHz}]$ & $\mathrm{THD}_{\mathrm{V}} \%$ & $\mathrm{THD}_{1} \%$ & $\mathrm{~V} \%$ & $\mathrm{Fc}[\mathrm{Hz}]$ & $\mathrm{P}[\mathrm{W}]$ & $\mathrm{P}_{\text {loss }}[\%]$ & $\mathrm{f}_{\mathrm{ob}}{ }^{\mathrm{A}}$ \\
\hline 5 & 3.32 & 9.04 & 3.77 & 1394 & 52.94 & 1.32 & 22.7 \\
\hline 10 & 4.09 & 5.60 & 3.23 & 1394 & 48.42 & 1.21 & 19.0 \\
\hline 15 & 2.48 & 3.92 & 3.54 & 1394 & 53.00 & 1.33 & 17.0 \\
\hline
\end{tabular}

Technical specifications of the filter $\mathrm{R}=15.32 \Omega, \mathrm{L}=5.08 \mathrm{mH}, \mathrm{C}=4.30 \mu \mathrm{F}$ designed for $f_{\text {sw }}=10 \mathrm{kHz}$

Table 8

\begin{tabular}{|c|c|c|c|c|c|c|c|}
\hline $\mathrm{f}_{\mathrm{sw}}[\mathrm{kHz}]$ & $\mathrm{THD}_{\mathrm{V}} \%$ & $\mathrm{THD}_{1} \%$ & $\Delta \mathrm{V} \%$ & $\mathrm{Fc}[\mathrm{Hz}]$ & $\mathrm{P}[\mathrm{W}]$ & $\mathrm{P}_{\text {loss }}[\%]$ & $\mathrm{f}_{\mathrm{ob}}{ }^{\mathrm{A}}$ \\
\hline 5 & 5.64 & 7.57 & 4.40 & 1730 & 53.15 & 1.32 & 24.2 \\
\hline 10 & 3.88 & 5.04 & 3.71 & 1730 & 46.88 & 1.17 & 18.5 \\
\hline 15 & 2.72 & 3.22 & 4.13 & 1730 & 46.86 & 1.17 & 15.9 \\
\hline
\end{tabular}

Technical specifications of the filter $\mathrm{R}=13.88 \Omega, \mathrm{L}=4.26 \mathrm{mH}, \mathrm{C}=1.75 \mu \mathrm{F}$ designed for $f_{s w}=15 \mathrm{kHz}$

Table 9

\begin{tabular}{|c|c|c|c|c|c|c|c|}
\hline $\mathrm{f}_{\mathrm{sw}}[\mathrm{kHz}]$ & $\mathrm{THD}_{\mathrm{V}} \%$ & $\mathrm{THD}_{1} \%$ & $\Delta \mathrm{V} \%$ & $\mathrm{Fc}[\mathrm{Hz}]$ & $\mathrm{P}[\mathrm{W}]$ & $\mathrm{P}_{\text {loss }}[\%]$ & $\mathrm{f}_{\mathrm{ob}}{ }^{\mathrm{A}}$ \\
\hline 5 & 9.66 & 9.78 & 3.96 & 2902 & 51.46 & 1.29 & 29.8 \\
\hline 10 & 5.01 & 5.84 & 3.27 & 2902 & 46.67 & 1.17 & 19.9 \\
\hline 15 & 5.27 & 4.28 & 3.98 & 2902 & 47.98 & 1.20 & 14.0 \\
\hline
\end{tabular}


Optimal filter configurations achieved considering different loads

Table 10

\begin{tabular}{|c|c|c|c|c|c|c|c|c|}
\hline $\mathrm{T}_{\mathrm{L}}[\mathrm{Nm}]$ & $\mathrm{R}[\Omega]$ & $\mathrm{L}[\mathrm{mH}]$ & $\mathrm{C}[\mu \mathrm{F}]$ & $\mathrm{THD}_{\mathrm{V}} \%$ & $\mathrm{THD}_{1} \%$ & $\Delta \mathrm{V} \%$ & $\mathrm{P}_{\text {loss }}{ }^{\circ}$ & $\mathrm{f}_{\mathrm{ob}}{ }^{\mathrm{A}}$ \\
\hline 0 & 1.2 & 14.2 & 8.0 & 0.43 & 7.69 & 6.5 & 0.17 & 15.5 \\
\hline 10 & 25.5 & 9.0 & 4.2 & 4.95 & 6.58 & 5.3 & 0.6 & 19.9 \\
\hline 20 & 7.7 & 4.3 & 7.5 & 3.32 & 9.04 & 3.8 & 1.32 & 22.7 \\
\hline
\end{tabular}

Technical specifications of the filter $R=1.23 \Omega, L=14.26 \mathrm{mH}, C=8.01 \mu \mathrm{F}$ designed for $L o a d=0 \mathrm{Nm}$

Table 11

\begin{tabular}{|c|c|c|c|c|c|c|cc|}
\hline $\mathrm{T}_{\mathrm{L}}[\mathrm{Nm}]$ & $\mathrm{THD}_{\mathrm{V}} \%$ & $\mathrm{THD}_{1} \%$ & $\Delta \mathrm{V} \%$ & $\mathrm{~F}_{\mathrm{C}}[\mathrm{Hz}]$ & $\mathrm{P}[\mathrm{W}]$ & $\mathrm{P}_{\text {loss }} \%$ & $\mathrm{f}_{\mathrm{ob}}{ }^{\mathrm{A}}$ \\
\hline 0 & 0.44 & 7.65 & 6.53 & 731 & 6.76 & 0.17 & 15.4 \\
\hline 10 & 0.63 & 6.50 & 9.35 & 731 & 17.74 & 0.44 & 18.7 \\
\hline 20 & 0.86 & 0.93 & 51.77 & 731 & 420.84 & 10.52 & 106.2 \\
\hline
\end{tabular}

start-up with a $V / f=$ const. control strategy, with different load values and filter sets. It can be observed that filters sized for lower loads cannot be adopted at high currents because they produce significant voltage drops, which affects the torque capability of the motor. As a matter of fact, the first two filter sets affect the maximum motor torque, excluding the possibility to run the drive at rated load.

\section{(c) Power Rating}

In order to confirm the general validity of the proposed design technique regardless drive power ratings, a $15 \mathrm{~kW}$ induction motor drive was also taken into consideration, operating at different switching frequencies and loads, with $m_{a}=0.9$ and rated motor frequency. The calculated filters are listed in Table 14 together with the corresponding performance.

In order to limit the THDs, voltage drops and losses, the capacitor $C$ value provided by the designed procedure is increased

Technical specifications of the filter $R=25.52 \Omega, L=9.07 \mathrm{mH}, C=4.16 \mu \mathrm{F}$ designed for $\mathrm{Load}=10 \mathrm{Nm}$

Table 12

\begin{tabular}{|c|c|c|c|c|c|c|c|}
\hline $\mathrm{T}_{\mathrm{L}}[\mathrm{N} \times \mathrm{m}]$ & $\mathrm{THD}_{\mathrm{V}} \%$ & $\mathrm{THD}_{1} \%$ & $\Delta \mathrm{V} \%$ & $\mathrm{~F}_{\mathrm{C}}[\mathrm{Hz}]$ & $\mathrm{P}[\mathrm{W}]$ & $\mathrm{P}_{\text {loss }} \%$ & $\mathrm{f}_{\mathrm{ob}}{ }^{\mathrm{A}}$ \\
\hline 0 & 4.89 & 10.98 & 4.60 & 1338 & 11.30 & 0.28 & 21.9 \\
\hline 10 & 4.92 & 7.07 & 5.34 & 1338 & 21.69 & 0.54 & 20 \\
\hline 20 & 7.81 & 1.19 & 40.31 & 1338 & 634.65 & 15.87 & 128.6 \\
\hline
\end{tabular}

Technical specifications of the filter $R=7.76 \Omega, L=4.33 \mathrm{mH}, C=7.51 \mu \mathrm{F}$ designed for $L o a d=20 \mathrm{Nm}$

Table 13

\begin{tabular}{|c|c|c|c|c|c|c|c|}
\hline $\mathrm{T}_{\mathrm{L}}[\mathrm{N} \times \mathrm{m}]$ & $\mathrm{THD}_{\mathrm{V}} \%$ & $\mathrm{THD}_{1} \%$ & $\Delta \mathrm{V} \%$ & $\mathrm{~F}_{\mathrm{C}}[\mathrm{Hz}]$ & $\mathrm{P}[\mathrm{W}]$ & $\mathrm{P}_{\text {loss }} \%$ & $\mathrm{f}_{\mathrm{ob}}{ }^{\mathrm{A}}$ \\
\hline 0 & 3.28 & 24.20 & 2.17 & 1395 & 10.90 & 0.27 & 31 \\
\hline 10 & 3.30 & 15.47 & 2.74 & 1395 & 20.70 & 0.52 & 24.1 \\
\hline 20 & 3.34 & 9.02 & 3.77 & 1395 & 52.96 & 1.32 & 22.8 \\
\hline
\end{tabular}

Filter specifications for different loads and switching freq.

Table 14

\begin{tabular}{|c|c|c|c|c|c|c|c|c|c|}
\hline $\mathrm{f}_{\mathrm{sw}}[\mathrm{kHz}]$ & $\mathrm{T}_{\mathrm{L}}[\mathrm{N} \times \mathrm{m}]$ & $\mathrm{R}[\Omega]$ & $\mathrm{L}[\mathrm{mH}]$ & $\mathrm{C}[\mu \mathrm{F}]$ & $\mathrm{THD}_{\mathrm{V}} \%$ & $\mathrm{THD}_{1} \%$ & $\Delta \mathrm{V} \%$ & $\mathrm{P}_{\mathrm{p}} \%$ & $\mathrm{f}_{\mathrm{ob}}{ }^{\mathrm{A}}$ \\
\hline 5 & 0 & 1.04 & 7.1 & 42.9 & 0.4 & 6.6 & 7.5 & 1.2 & 20.5 \\
\hline 5 & 40 & 5.23 & 2.3 & 16.3 & 3.9 & 9.1 & 5.4 & 4.7 & 42.3 \\
\hline 5 & 60 & 10.3 & 1.9 & 8.5 & 9.5 & 7.0 & 6.4 & 9.7 & 71.5 \\
\hline 15 & 0 & 4.18 & 4.2 & 10.7 & 0.4 & 6.6 & 6.0 & 1.6 & 22.0 \\
\hline 15 & 40 & 5.57 & 2.5 & 16.0 & 1.9 & 6.2 & 6.2 & 5.1 & 22.0 \\
\hline 15 & 60 & 15.2 & 1.8 & 4.9 & 5.6 & 4.5 & 5.9 & 8.9 & 60.5 \\
\hline
\end{tabular}


while the inductor $L$ values are decreased with respect to those used for the $4 \mathrm{~kW}$ motor drive. Moreover, similar results regarding the switching frequency and load dependence are confirmed also in these cases.

\section{(d) Investment cost}

In the previous analysis the investment costs were not included in the object function, thus excluding the economic aspect from the filter design. The results reported in Table 15 were achieved by using the object functions $f_{o b}{ }^{B}$ and $f_{o b}{ }^{C}$ and considering a $4 \mathrm{~kW}$ motor drive operating at rated conditions and $f_{s w}=5 \mathrm{kHz}$. It is adequate to note that as the weight associated to IC $\left(f_{o b}{ }^{C}\right)$ is increased a considerable reduction of the capacitor value $\mathrm{C}$ is pointed out, yielding to an increment of voltage drop and THDV. On the contrary, the bandwidth of the filter is increased.

\section{Conclusions and future works}

In this paper, the filter design method based on GA and recursive simulations was proposed. Such a technique can be assumed as a valid alternative to standard design procedures as it allows to provide high performance filter arrangement without exploiting complicated analytical studies while contemporarily consider design constraints of both technical and economic nature.

The method was also used as a tool to analyze the impact of each technical constraint on filter parameters and it also allows evaluating the effects of parameter variation on filter performance.

Although the proposed methodology was tested adopting a simple filter topology, it can be suitably applied to more complex filtering systems, thus represents a very useful tool especially in the case of complex filter topologies. Moreover, many design constraints can be also included, such as high frequency common mode currents and overvoltage at motor terminals which are really difficult to manage with standard methods at the same time with all other constraints.
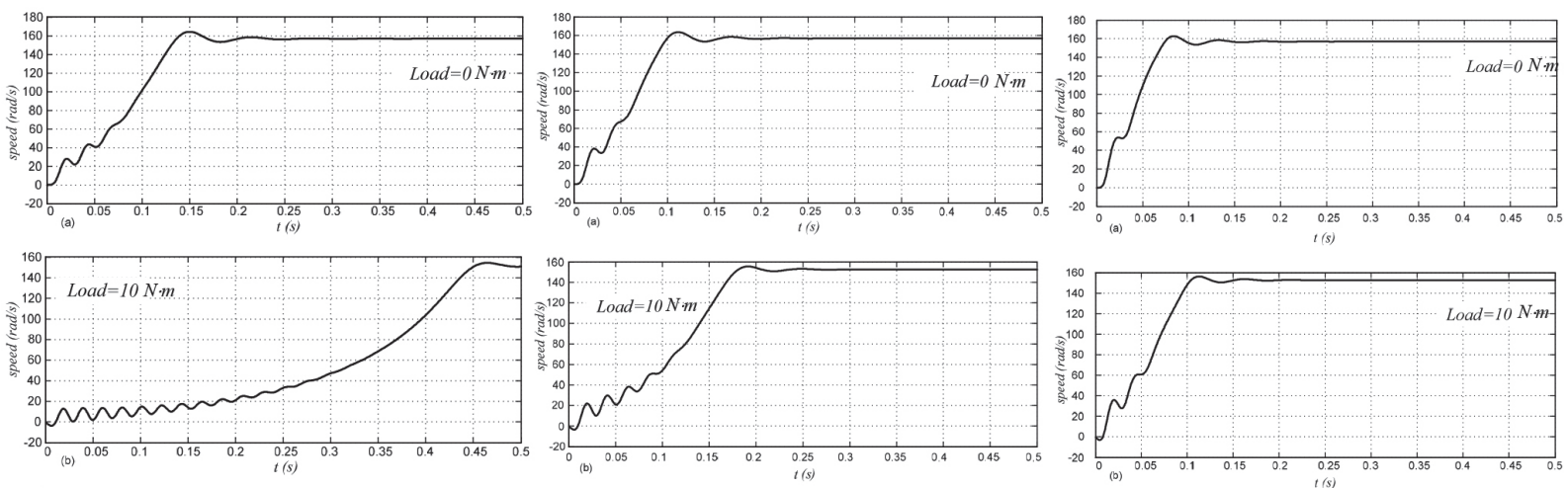

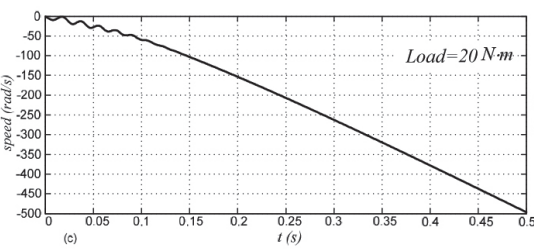

Filter of Table 11

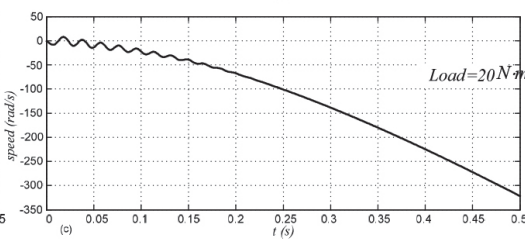

Filter of Table 12

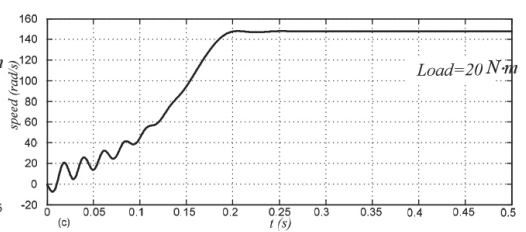

Filter of Table 13

Fig. 5 Speed transition during the start-up of the drive at different loads using three filter configurations

Technical specifications of the filters including investment cost

Table 15

\begin{tabular}{|c|c|c|c|c|c|c|c|c|c|}
\hline & $\mathrm{THD}_{\mathrm{V}} \%$ & $\mathrm{THD}_{1} \%$ & $\Delta \mathrm{V} \%$ & $\mathrm{R}[\Omega]$ & $\mathrm{L}[\mathrm{mH}]$ & $\mathrm{C}[\mu \mathrm{F}]$ & $\mathrm{P}_{\text {loss }} \%$ & $\mathrm{~F}_{\mathrm{c}}[\mathrm{Hz}]$ & $\mathrm{IC}[€]$ \\
\hline$f_{o b}{ }^{B}$ & 3.50 & 7.42 & 4.4 & 9.2 & 5.21 & 5.22 & 1.3 & 1.52 & 67 \\
\hline$f_{o b}{ }^{C}$ & 4.46 & 6.75 & 5.0 & 7.3 & 5.82 & 2.52 & 1.3 & 2.05 & 64 \\
\hline
\end{tabular}




\section{References}

[1] VITTEK, J., FTOREK, B.: Energy Efficient Speed and Position Control of Electric Drives with PMSM, Communications - Scientific Letters of the University of Zilina, 16 (1), 2014, pp. 64-71.

[2] CACCIATO, M., CONSOLI, A., FINOCCHIARO, L., TESTA, A.: High Frequency Analysis and Modeling of Bearing Currents and Shaft Voltage on Electrical Motors, Proc. of the IEEE Eighth Intern. Conference on Electrical Machines and Systems, ICEMS 2005, Nanjing, pp. 27-29 September 2005, pp. 2065-2070.

[3] SERPORTA, C., TINE, G., VITALE, G., DI PIAZZA, M. C.: Conducted EMI in Power Converters Feeding AC Motors: Experimental Investigation and Modelling, Proc. of the 2000 IEEE Intern. Symposium on Industrial Electronics, ISIE 2000, 2000, Cholula : Puebla, pp. 359-364.

[4] CACCiato, M., CAVAllaro, C., SCARCElla, G., TESTA, A.: Effects of Connection Cable Length on Conducted EMI in Electric Drives, Proc. of IEEE Intern. Conference on Electric Machines and Drives, IEMDC '99, 1999, Seattle, pp. 428-430.

[5] MOREIRA, A. F., SANTOS, P. M., LIPO, T. A., VENKATARAMANAN, G.: Filter Networks for Long Cable Drives and their Influence on Motor Voltage Distribution and Common-mode Currents, IEEE Transactions on Industrial Electronics, vol. 52, No. 2, 2005, pp. 515-522.

[6] SALOMAKI, J., HINKKANEN, M., LUOMI, J.: Cost-Effective Design of Inverter Output Filters for AC Drives, IEEE $33^{\text {rd }}$ Annual Conference of the Industrial Electronics Society, IECON 2007, pp. 1220-1226.

[7] HANigovsZKI, N., LANDKILDEhUS, J., BlAABJERG, F.: Output Filters for AC Adjustable Speed Drives, Proc. of Twenty Second Annual IEEE Applied Power Electronics Conference, APEC 2007, 2007, Anaheim, pp. 236-242.

[8] CACCIATO, M., DE CARO, S., SCARCELLA, G., SCELBA, G., TESTA, A.: Improved Space-Vector Modulation Technique for Common Mode Currents Reduction, IET Power Electronics, vol. 6, No. 7, 2013, pp. 1248-1256.

[9] DI PIAZZA, M. C., LUNA, M., VITALE, G.: EMI Reduction in DC-Fed Electric Drives by Active Common-Mode Compensator IEEE Transactions on Electromagnetic Compatibility, early access, 2014, pp.1-10.

[10] CACCiATO, M., CONSOli, A., SCARCElla, G., SCELBA, G., TESTA, A.: Modified Space-Vector-Modulation Technique for Common Mode Currents Reduction and Full Utilization of the DC Bus, Proc. of Twenty-Fourth Annual IEEE Applied Power Electronics Conference and Exposition, APEC 2009, Feb. 2009, Washington DC, pp. 109-115.

[11] VON JOUANNE, A., ENJETI, P. N.: Design Considerations for an Inverter Output Filter to Mitigate the Effects of Long Motor Leads in ASD Applications, IEEE Transactions on Industry Applications, vol. 33, No. ${ }^{\circ}$, 1997, pp. 1138-1145.

[12] LEE-HUN K., HWAN-KYUN Y., CHUNG-YUEN W., YOUNG-REAL K., GI-SU CH.: Output Filter Design for Conducted EMI Reduction of PWM Inverterfed Induction Motor System, IEEE International Conference on Power Electronics and Drive Systems 2001, pp. 252-258.

[13] SOZER, Y., TORREY, D. A., REVA, S.: New Inverter Output Filter Topology for PWM Motor Drives, IEEE Transactions on Power Electronics, vol. 15, No. ${ }^{\circ}$, 2000, pp. 1007-1017.

[14] ZUBI, H. M., DUNN, R. W., ROBINSON, F. V. P., EL-WERFELLI, M. H.: Passive Filter Design Using Genetic Algorithms for Adjustable Speed Drives, Proc. of IEEE Power and Energy Society General Meeting 2010, pp. 1-7.

[15] NORAINI, M. R., GERAGHTY, J: Genetic Algorithm Performance with Different Selection Strategies in Solving TSP, Proc. of the World Congress on Engineering, vol. II, WCE 2011, July, 2011, London

[16] LiSERRE, M., DELL'AQUILA, A., BLAABJERG, F.: Genetic Algorithm-based Design of the Active Damping for an LCL-filter Three-phase Active Rectifier, IEEE Transactions on Power Electronics, vol. 19, No. 1, pp. 76-86, 2004.

[17] DRGONA, P., PRIKOPOVA, A., FRIVALDSKY, M., PRIECINSKY, M.: Simulation Based Method for Design and Application of Digital Control System, Communications - Scientific Letters of the University of Zilina, vol. 13 (2A), 2011, pp. 32-37.

[18] SALOMAKI, J., HINKKANEN, M., LUOMI, J.: Influence of Inverter Output Filter on Maximum Torque and Speed of PMSM Drives, IEEE Transactions on Industry Applications, vol. 44, No. 1, pp. 153, 160, 2008.

[19] CACCIATO, M., CONSOLI, A., SCELBA, G., SCARCELlA, G.: An Effective Energy-saving Scalar Control for Industrial IPMSM Drives, IEEE Transactions on Industrial Electronics, vol. 60 (9), 2013, pp. 3658-3669.

[20] FRIVALDSKY, M., DOBRUCKY, B., SCELBA, G., SPANIK, P., DRGONA, P.: Bidirectional Step-up/step-down DC-DC Converter with Magnetically Coupled Coils, Communications - Scientific Letters of the University of Zilina, 15 (3), 2013, pp. 21-25.

[21] CACCIATO, M., CONSOLI, A., SCARCELlA, G., SCELBA, G.: Indirect Maximum Torque per Ampere Control of Induction Motor Drives, EPE J. (European Power Electronics and Drives J.), 18 (4), pp. 34-41. 